\title{
Respuesta clínica favorable al tratamiento tópico en caso de paraqueratosis granular
}

Favorable clinical response to topical treatment in case of granular parakeratosis

\author{
Manuela Gómez Londoño', Luz Adriana Vásquez Ochoa², Ana Cristina Ruiz Suárez ${ }^{3}$ \\ 1. Médica General, Universidad Pontificia Bolivariana, Medellín, Antioquia \\ 2. Médica, Dermatóloga, Hospital "Pablo Tobón Uribe", Medellín, Colombia \\ 3. Médica, Patóloga, Hospital "Pablo Tobón Uribe”, Medellín, Colombia
}

\section{RESUMEN}

La paraqueratosis granular es una entidad benigna que afecta principalmente las áreas intertriginosas y se asocia a la oclusión y contacto con sustancias irritantes. Fue descrita por primera vez en 1991 por Northcutt y colaboradores. La presentación clínica usual es la presencia de placas compuestas por pápulas foliculares hiperpigmentadas eritematosas y confluentes en pliegues axilares y, con menos frecuencia, en pliegues inguinales y glúteos de forma unilateral o bilateral. Afecta principalmente a las mujeres de mediana edad y responde bien al tratamiento con esteroides y retinoides tópicos. Se presenta el reporte de caso de una mujer de 36 años con diagnóstico de paraqueratosis granular axilar, con completa resolución de las lesiones con tretinoína y tracrolimús tópicos.

PALABRAS CLAVE: paraqueratosis granular, axilas, queratina.

\section{SUMMARY}

Granular parakeratosis is a benign entity that mainly affects the intertriginous areas and is associated with occlusion and contact with irritants. It was first described in 1991 by Northcutt et al. The usual clinical presentation is the presence of plaques composed of hyperpigmented follicular papules that are erythematous and confluent in axillary folds and less frequently, in inguinal folds and buttocks unilaterally or bilaterally. It mainly affects middle-aged women and have good answer to treatment with steroids and topical retinoids. We present the case report of a 36-year-old woman diagnosed with granular axillary parakeratosis, with complete resolution of tretinoin and topical tracrolimus lesions.

KEY WORDS: Granular paraqueratosis, armpit, keratin.

\section{INTRODUCCIÓN}

La paraqueratosis granular es una dermatosis benigna, descrita por primera vez en 1991 por Northcutt y colaboradores ${ }^{(1)}$. Se trata de una alteración histológica con características clínicas variables en áreas intertriginosas, más comúnmente en pliegues axilares, aunque también se han descrito casos ocasionales en pliegues inguinales y glúteos. La mayoría de los casos descritos se han encontrado en mujeres jóvenes, con

\author{
Correspondencia: \\ Manuela Gómez Londoño \\ Email: \\ manuela_gll@hotmail.com \\ Recibido: 15/07/19 \\ Aceptado: 19/08/19
}

Conflictos de interés:

No se reportan conflictos de interés.

Financiación:

Ninguna. 
edad promedio de 20 a 40 años; sin embargo, hay casos reportados en niños menores de 5 años. El diagnóstico confirmatorio se realiza con el estudio histopatológico $(2,3)$.

Clínicamente se caracteriza por la presencia de placas hiperpigmentadas compuestas por pápulas café-eritematosas con distribución lineal en los pliegues. Dichas placas pueden presentar ocasionalmente descamación, prurito, dolor o escaso eritema perilesional y pueden ser unilaterales o bilaterales. En los niños, la manifestación clínica más común es la presencia de placas en pliegues inguinales asociada al uso del pañal y de ropa oclusiva. Esta entidad generalmente empeora con la aplicación de agentes tópicos irritantes tales como antitranspirantes o cosméticos, asociado al uso de prendas que generan oclusión. Se consideran factores predisponentes la obesidad, la hiperhidrosis y el hirsutismo ${ }^{(4,5)}$.

El tratamiento de elección son los esteroides, retinoides e inhibidores de la calcineurina tópicos, en conjunto con las medidas generales que consisten en la suspensión del agente irritante y del uso de ropas oclusivas. Es común que después del manejo persista hiperpigmentación posinflamatoria ${ }^{(3)}$.

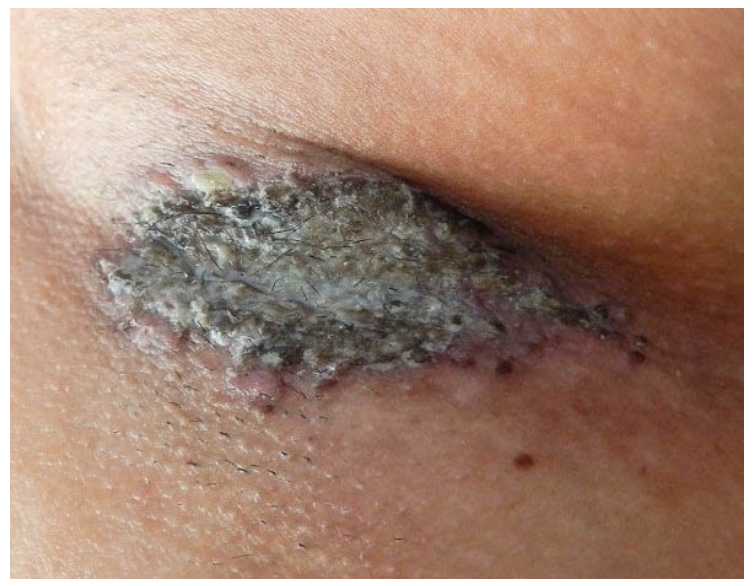

Figura 1. Placa hipertrófica hiperpigmentada con pápulas foliculares confluentes en la región axilar.

\section{CASO CLÍNICO}

Paciente femenina de 36 años, natural y residente en Medellín, Colombia, sin antecedentes patológicos de importancia, quien consultó al Hospital "Pablo Tobón Uribe” por historia de cuatro meses de evolución de placas compuestas por pápulas café, pruriginosas y dolorosas en ambas axilas, que empeoraban con el afeitado y el uso de antitranspirantes. Al examen físico se encontró una paciente con fototipo III, quien presentaba placas hipertróficas en ambas axilas compuestas por múltiples pápulas foliculares de color café, las cuales eran confluentes y tenían eritema perilesional (figura 1).

Ante la sospecha diagnóstica de pénfigo vegetante o enfermedad de Hailey-Hailey, se inició tratamiento con un ciclo corto de mometasona tópica, con poca mejoría. Dada la persistencia de las placas axilares, se realizó biopsia de la lesión y se encontró en el estudio histopatológico una epidermis acantósica, paraqueratosis y gránulos de queratohialina intracórneos (figura 2).

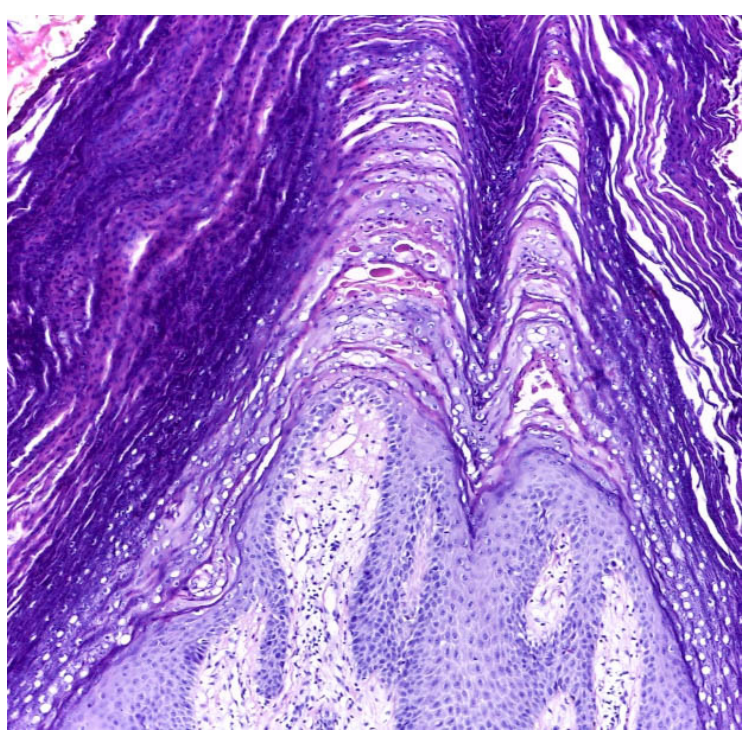

Figura 2. Acantosis de la epidermis, paraqueratosis y gránulos de queratohialina intracórneos. 


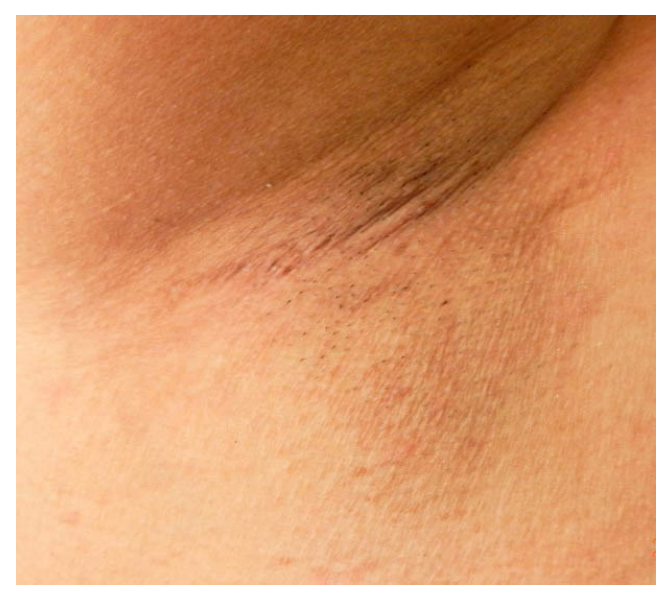

Figura 3. Región axilar postratamiento sin lesiones.

Con dichos hallazgos se descartaron las enfermedades inicialmente sospechadas y se confirmó el diagnóstico de paraqueratosis granular axilar. Se instauró tratamiento con tretinoína tópica, 2 días a la semana, en conjunto con tacrolimús, 5 días a la semana, por un periodo de 3 meses, con lo que se obtuvo finalmente la mejoría total de las lesiones (figura 3).

\section{DISCUSIÓN}

La paraqueratosis granular es una enfermedad benigna e infrecuente ${ }^{(2)}$, con reportes ocasionales en Estados Unidos, Europa y Australia (3). Fue descrita por primera vez en 1991 por Northcutt en 4 pacientes con placas hiperpigmentadas cafés-eritematosas, bien delimitadas, friables con prurito variable, de predominio axilar, como es el caso de la paciente descrita. Posteriormente, otros autores describieron presentaciones menos frecuentes en pliegues inguinales, abdominales, perianales y submamarios ${ }^{(4)}$.

La etiología es desconocida. La hipótesis más aceptada es la de Norcutt, en la que se cree que existe un defecto histológico en la maduración de la epidermis, específicamente en la transformación de profilagrina a filagrina, lo que da como resultado la permanencia de gránulos de queratohialina en el estrato córneo durante la cornificación ${ }^{(4,5)}$.

Esta entidad se puede presentar en personas de ambos sexos y a cualquier edad, aunque es más frecuente en mujeres jóvenes. No hay predilección racial y no existe una relación clara con enfermedades sistémicas ${ }^{(3)}$.
Se consideran factores desencadenantes la obesidad, la presencia de irritantes químicos, la oclusión y la hiperhidrosis. También el uso de ciertos alérgenos, como los antitranspirantes, que causan daño de la barrera dermoepidérmica ${ }^{(6,7)}$.

Los hallazgos más comunes en la histopatología son hiperqueratosis grave con conservación del estrato granuloso ${ }^{(5)}$, asociado a retención de gránulos de queratohialina e infiltrado inflamatorio de predominio CD4 positivos en estrato córneo, alteración de infundíbulos foliculares, proliferación vascular con infiltrado linfocítico perivascular, atrofia y acantosis de la epidermis con papilomatosis de aspecto psoriasiforme y vacuolización del estrato espinoso, que se observan claramente con la coloración de hematoxilina y eosina $(2,3,5)$.

Clínicamente se presenta con pápulas hiperpigmentadas cafés y eritematosas con superficie queratósica, que suelen confluir y formar placas lineales o geométricas descamativas con prurito variable, principalmente en la región axilar unilateral o bilateral o, con menor frecuencia, en el cuero cabelludo, abdomen, pliegues inguinales, vulva, periné, glúteos, rodillas y región submamaria. Las lesiones pueden persistir durante meses con períodos de remisión y exacerbación y ser recurrentes aun después del tratamiento ${ }^{(1,4,6,8)}$.

Dentro de los diagnósticos diferenciales se debe tener en cuenta la enfermedad de Hailey-Hailey, el pénfigo vegetante, la enfermedad de Fox Fordyce, la enfermedad de Darier, la acantosis nigricans, la psoriasis 
inversa, el liquen plano, la candidiasis, el eritrasma, la dermatosis neglecta y la dermatitis de $\operatorname{contacto}^{(9,10)}$.

En los niños, esta entidad tiene un pico de incidencia de presentación de los 10 a los 24 meses, y a diferencia de los adultos, la mayoría de los casos se presentan en el área del pañal, especialmente en los puntos de mayor presión, exacerbándose las lesiones con temperaturas altas, productos cosméticos y el sudor (11). En este grupo etario el diagnóstico diferencial más importante es la dermatitis del pañal, cuyo hallazgo común en la histopatología es la hiperqueratosis, con acantosis, ortoqueratosis y paraqueratosis, con la diferencia de la retención de los gránulos de queratohialina, que es el hallazgo patognomónico de la paraqueratosis granular ${ }^{(3,6)}$.

El manejo de elección son los esteroides tópicos de mediana o alta potencia, ya que se ha visto que aceleran el paso de profilagrina a filagrina. Los derivados de la vitamina D son útiles, ya que inhiben la proliferación de los queratinocitos y su diferenciación. Los retinoides interfieren en el proceso de queratinización, con buenos resultados. Otros tratamientos descritos son la crioterapia, con mejoría en algunos casos. En todos los pacientes deben suspenderse los factores desencadenantes. Es común encontrar hiperpigmentación postinflamatoria una vez resueltas las lesiones, en cuyo caso se recomienda el uso de despigmentantes tópicos o de radiofrecuencia $(1,3,4,5)$.

El caso descrito es concordante con los reportes previamente publicados en la literatura: se presenta en la población más susceptible y con un cuadro clínico e histológico típico. Es de resaltar en este caso la marcada respuesta al tratamiento tópico insaturado, sin hiperpigmentación residual y con una resolución completa de las lesiones, sin recidivas en los controles posteriores.

\section{CONCLUSIONES}

- La paraqueratosis granular es un trastorno benigno de la queratina, que afecta áreas intertriginosas. Es infrecuente, por lo cual no suele ser la primera impresión diagnóstica del médico tratante.

- $\quad$ El diagnóstico se confirma por biopsia, con los hallazgos histopatológicos característicos descritos.

- La enfermedad tiene una notable respuesta al tratamiento con retinoides, inhibidores de la calci- neurina y esteroides tópicos, en la mayoría de los casos evolucionando a la resolución completa.

- Muchos casos se resuelven con la suspensión del irritante u oclusión local.

- Se presenta el caso de una mujer con paraqueratosis granular axilar con excelente respuesta a retinoide y tacrolimús tópicos.

\section{REFERENCIAS}

1. Ramos C, Álvarez P, Salomón M. Paraqueratosis granular. Folia Dermatol Peru. 2006;17(3):137-40.

2. Chávez L, Cárdenas M, González G. Paraqueratosis granular inguinal. Med Cutan Iber Lat Am. 2013;41(5):236-8.

3. Scheinfeld NS, Mones J. Granular parakeratosis: pathologic and clinical correlation of 18 cases of granular parakeratosis. J Am Acad Dermatol. 2005;52(5):863-7.

4. Ding CY, Liu H, Khachemoune A. Granular parakeratosis: A comprehensive review and a critical reappraisal. Am J Clin Dermatol. 2015;16(6):495-500.

5. Metze D, Rütten A. Granular Parakeratosis -- a unique acquired disorder of keratinization. J Cutan Pathol. 1999;26(7):339-52.

6. Barnes C, Lesher J Jr, Sangueza O. Axillary granular parakeratosis. Int J Dermatol. 2001;40(7):439-41.

7. Prieto J, López N, Gallego E. Paraqueratosis granular, una rara entidad, a propósito de un caso. Rev Esp Patol. 2017;50(3):137-20.

8. Varela C, Rueda R. Paraqueratosis granular axilar unilateral de inicio macular. Rev Asoc Colomb Dermatol. 2018;26(1):32-5.

9. González M, Valles M, Polo R. Paraqueratosis granular. Actas Dermosifiliogr. 2007;98:355-7.

10. Rodríguez G. Paraqueratosis granulosa de la axila. Biomédica. 2002;22:519-23.

11. Galvis W, Jaramillo F, Soto C. Paraqueratosis granulosa en niños. Rev Asoc Colom Dermatol. 2012;20(2):192-5. 